\title{
Sistem Informasi Administrasi Pasien Rawat Jalan Berbasis Website Pada Klinik Pratama Menara Gading Wangon
}

\author{
Vembria Rose Handayani ${ }^{1}$, S. Suripah ${ }^{2}$, Annisa Ika Restiana Putri ${ }^{3}$ \\ ${ }^{123}$ Sistem Informasi, Universitas Bina Sarana Informatika \\ Indonesia
}

E-mail:vembria.vrh@bsi.ac.id, suripah.sih@bsi.ac.id,annisairp@gmail.com

\begin{abstract}
Everyone has the right to get access for good health services, quality, safe, effective and affordable health services. The service at Klinik Pratama Menara Gading actually still looks not optimal. With enough amount of patients who come every day makes the clinic difficulties in the process of administration of patients ranging from registration, recording of medical records, medical prescription until reports and clinical administration costs. The solution of the problem is develop a website-based outpatient administration information system. With this solution can reduce the occurrence of data duplication and unwanted errors, so it can improve performance more effectively and efficiently.
\end{abstract}

Keywords: Information System; Administration; Website; Clinic; Services

Abstrak - Setiap orang memiliki hak untuk mendapatkan akses pelayanan kesehatan yang baik, bermutu, aman, efektif dan terjangkau. Pelayanan di Kinik Pratama Menara Gading ini masih terlihat belum optimal. Dengan cukup banyaknya pasien yang datang setiap harinya membuat pihak klinik kesulitan dalam proses administrasi pasien mulai dari pendaftaran, pencatatan rekam medis, resep obat sampai dengan laporan dan biaya administrasi klinik. Solusi dari masalah tersebut yaitu membangun sistem informasi administrasi pasien rawat jalan berbasis website. Dengan adanya solusi ini dapat mengurangi terjadinya duplikasi data dan kesalahan yang tidak diinginkan, sehingga dapat meningkatkan kinerja yang lebih efektif dan efisien.

Kata kunci: Sistem Informasi; Administrasi; Website; Klinik; Pelayanan

\section{PENDAHULUAN}

Kesehatan merupakan suatu hal yang selalu diinginkan oleh setiap orang agar dapat bekerja atau melakukan aktivitas sehari harinya. Karena itulah setiap orang berusaha untuk menjaga kesehatannya masing-masing. Namun ada kalanya seseorang lalai menjaga kesehatannya atau tanpa disadari tiba-tiba kesehatannya menurun. Sehingga mengakibatkan memang harus memeriksakan kesehatan ke dokter di rumah sakit, puskemas atau klinik. Dan semakin meningkatnya orang untuk 
memeriksakan kesehatan sudah seharusnya diiringi dengan peningkatan pelayan kesehatan.

Masyarakat memiliki hak untuk mendapatkan pelayanan kesehatan yang baik. Menurut (Rahmayu, 2016) bahwa "banyak rumah sakit yang masih menggunakan proses manual dalam pengolahan datanya, sehingga banyak pasien yang harus menunggu lama untuk melakukan transaksi pada saat memerlukan perawatan medis, seperti saat menunggu giliran check up, melakukan pengambilan obat dan melakukan transaksi pembayaran". Menurut penelitian yang dilakukan oleh (Hadiyati, Sekarwana, Sunjaya, \& Setiawati, 2017) bahwa "pasien mengharapkan pengurangan waktu tunggu disetiap pelayanan, berharap ketertiban dalam prosedur administratif dan berharap tidak terdapat tindakan curang dalam proses administrasi". "E-Service merupakan layanan melalui internet yang biasanya mengacu pada peran teknologi dalam memfasilitasi pelayanan yang membuat mereka lebih dari layanan elektronik" (Sundari, 2016).

Klinik Pratama Menara Gading Wangon merupakan suatu institusi pelayanan kesehatan rawat jalan yang terdiri dari 2 poli yaitu poli umum dan poli gigi kepada masyarakat umum dan Badan Penyelenggara Jaminan Sosial (BPJS).
Pelayanan klinik masih terlihat belum optimal, dengan cukup banyaknya pasien yang datang setiap harinya membuat pihak klinik kesulitan dalam proses administrasi pasien rawat jalan mulai dari dari pendaftaran, pemeriksaan, apotek sampai dengan laporan dan biaya administrasi klinik yang masih dilakukan manual, menggunakan media kertas dalam proses pencatatannya.

Pada saat pendaftaran pasien baru dan pasien lama, petugas harus mencatat data pasien yang berobat setiap harinya kedalam buku besar dan mencari data pasien yang kemudian dicocokan sesuai dengan kartu pasien pasien satu per satu pada dokumen yang tersimpan di rak. Selanjutnya pada bagian pemeriksaan dokter harus mencatat data diagnosa dan resep obat pasien pada kartu rekam medis yang masih menggunakan arsip berupa kertas. Pada bagian apotek, petugas harus mencari stok obat yang diterima pasien satu per satu. Dan mencatat data transaksi administrasi pasien ke dalam buku besar berdasarkan struk pembayaran administrasi pasien tersebut.

Ada beberapa peneliti yang melakukan penelitian berkaitan dengan sistem informasi administrasi berbasis web di rumah sakit. Penelitian yang dilakukan oleh (Syahabiah, Gusmelia Testiana, 2016) menghasilkan kesimpulan bahwa sistem informasi administrasi berbasis web pada 
Klinik Su'adah dapat memproses semua data pasien, dokter, pendaftaran, pembayaran, history rekam medis, kemudahan proses pendaftaran secara online serta menghasilkan laporan pendaftaran dan pembayaran dengan lebih cepat dan akurat. Penelitian yang dibuat oleh (Handayani \& Feoh, 2016), sistem informasi rekam medis berbasis web dapat melakukan registrasi, pencatatan rekam medis pasien rawat inap, pencatatan data dokter, pencatatan data ruang, serta menghasilkan laporan laporan administrasi yang dibutuhkan pihak manajemen untuk pengambilan keputusan dan informasi rekam medis pasien untuk klaim asuransi. Menurut hasil penelitian yang dilakukan oleh (Magdalena \& Ramadhan, 2018) bahwa sistem informasi berbasis web yang sengaja dirancang untuk meningkatkan mutu layanan administrasi UGD serta mempermudah petugas UGD, Dokter dan keluarga pasien dalam mendata semua kelengkapan informasi untuk kelancaran proses rawat jalan maupun rawat inap di UGD Rumah Sakit Bakti Timah Pangkalpinang. Penelitian yang dibuat oleh (Syahriani, 2018) menghasilkan kesimpulan bahwa sistem ini dibuat berbasis web dengan menggunakan jaringan intranet. Sistem ini dapat melakukan pendaftaran pasien baru, pengambilan nomor antrian pasien berobat dan rekam medis.
Berdasarkan pembahasan diatas terutama khususnya permasalahan yang terjadi pada Klinik Pratama Menara Gading Wangon maka penelitian ini berfokus pada upaya merancang aplikasi berbasis web dengan menggunakan jaringan intranet untuk mempermudah dan mempercepat keadministrasian pasien. Dengan dukungan teknologi informasi yang ada sekarang ini, komputer menjadi salah satu bagian yang sangat penting dari sistem informasi karena kemampuannya dalam memproses data. Dengan adanya sistem informasi yang cepat, mudah dan akurat dapat mengurangi terjadinya kesalahan yang tidak diinginkan, sehingga dapat meningkatkan kinerja yang lebih efektif dan efisien.

\section{METODOLOGI PENELITIAN}

\subsection{Metode Pengembangan Perangkat} Lunak

Metode yang digunakan pada pengembangan perangkat lunak ini menggunakan metode waterfall atau model air terjun. Menurut Rosa dan Shalahuddin dalam (Supriyanta \& Nussy, 2016) tahapan model SDLC air terjun (waterfall) atau model sekuensial liner (sequential linear) adalah:

a. Analisis kebutuhan perangkat lunak

Proses pengumpulan kebutuhan dilakukan secara intensif untuk mencari spesifikasi kebutuhan perangkat lunak agar 
dapat dipahami perangkat lunak seperti apa yang tepat dan dibutuhkan oleh user.

\section{b. Desain}

Desain perangkat lunak adalah proses multi langkah yang fokus pada desain pembuatan program perangkat lunak termasuk struktur data, arsitektur perangkat lunak, representasi antarmuka dan prosedur pengkodean. Tahap ini mentranslasi kebutuhan perangkat lunak dari tahap analisis kebutuhan ke representasi desain agar dapat diimplementasikan menjadi program pada tahap selanjutnya.

c. Pembuatan kode program

Hasil dari tahap ini adalah pembuatan program komputer yang sesuai dengan desain yang telah dibuat pada tahap desain.

d. Pengujian

Pengujian fokus pada perangkat lunak dari segi logika dan fungsional serta memastikan bahwa semua bagian sudah diuji. Hal ini dilakukan untuk meminimalisir kesalahan (error) dan memastikan keluaran yang dihasilkan sesuai dengan yang diinginkan.

e. Pendukung (support) atau Pemeliharaan (maintenance)

Tidak menutup kemungkinan sebuah perangkat lunak mengalami perubahan ketika sudah dikirimkan ke user. Perubahan bisa terjadi karena adanya kesalahan yang muncul dan tidak terdeteksi saat pengujian atau perangkat lunak harus beradaptasi dengan lingkungan baru. Proses ini juga menjaga agar program yang sudah dibuat berjalan sebagaimana mestinya, sesuai yang diharapkan.

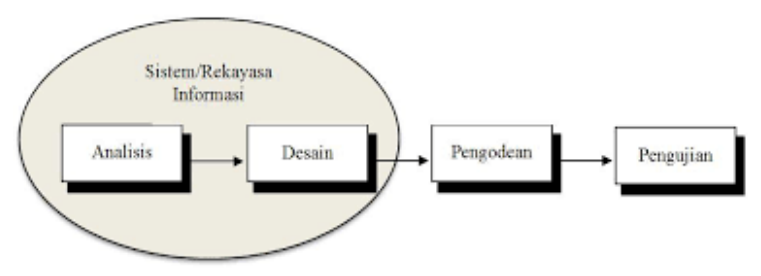

Sumber : Rosa dan Shalahuddin dalam (Supriyanta \& Nussy, 2016)

Gambar II.1. Metode Pengembangan

Perangkat Lunak (Waterfall)

\subsection{Teknik Pengumpulan Data}

a. Metode Wawancara

Metode dengan pengumpulan data berupa tanya jawab dengan pemilik Klinik Pratama Menara Gading mengenai semua yang berhubungan dengan sistem administrasi pasien rawat jalan.

b. Metode Observasi

Metode ini dilakukan dengan cara observasi atau mengamati langsung kegiatan yang ada di Klinik Pratama Menara Gading kemudian mencatat halhal penting yang berhubungan dengan sistem administrasi pasien rawat jalan.

c. Metode Studi Pustaka

Informasi yang diperoleh dari berbagai buku, jurnal, majalah, internet dan sumber-sumber lainnya. 
halaman pendaftaran.

\section{HASIL DAN PEMBAHASAN}

\subsection{Analisa Kebutuhan}

a. Analisis Kebutuhan Fungsional

Merupakan bentuk proses yang dibutuhkan oleh user dalam mengakses sebuah website berdasarkan kriteria dan fungsinya.

Adapun beberapa kebutuhannya sebagai berikut :

1) Kebutuhan Administrator

- Admin dapat melakukan Login ke halaman admin.

- Admin dapat melihat form pendaftaran.

- Admin dapat melihat form dokter.

- Admin dapat melihat form apoteker.

- Admin dapat mengelola data pasien.

- Admin dapat melihat antrian pasien yang sedang berjalan.

- Admin dapat mengelola data dokter.

- Admin dapat mengelola data tindakan.

- Admin dapat mengelola data obat.

- Admin dapat mengelola data poliklinik.

- Admin dapat mengelola data jaminan sosial.

- Admin dapat mengelola data user.

- Admin dapat menghapus seluruh antrian.

- Admin dapat mengelola data klinik.

2) Kebutuhan Petugas Pendaftaran

- Petugas dapat melakukan Login ke
- Petugas dapat mengelola data pasien.

- Petugas dapat mencetak kartu pasien.

- Petugas dapat mengelola surat rujukan.

- Petugas dapat melihat antrian pasien.

- Petugas dapat mengubah password.

3) Kebutuhan Dokter

- Dokter dapat melakukan Login ke halaman pendaftaran.

- Dokter dapat melihat antrian pasien berdasarkan poli.

- Dokter dapat melihat riwayat rekam medis pasien.

- Dokter dapat mencatat diagnosa.

- Dokter dapat menambah tindakan.

- Dokter dapat menambah obat.

- Dokter dapat mengubah password.

4) Kebutuhan Apoteker

- Apoteker dapat melakukan Login ke halaman apoteker.

- Apotaker dapat mengelola data obat.

- Apoteker dapat mengklaim jaminan sosial.

- Apoteker dapat melakukan cetak pada rincian pembayaran.

- Apoteker dapat membuat laporan data pasien menurut jaminan sosial dan poliklinik.

- Dapat mengubah password.

b. Analisis Kebutuhan Keamanan

Memerlukan sistem keamanan agar terhindar dari pihak yang tidak bertanggungjawab yaitu password 
administrator, petugas pendaftaran, dokter dan apoteker dienkripsi menggunakan fungsi md5 agar tidak diketahui oleh pihak lain.

\subsection{Rancangan Basis Data}

a. Entity Relationship Diagram (ERD)

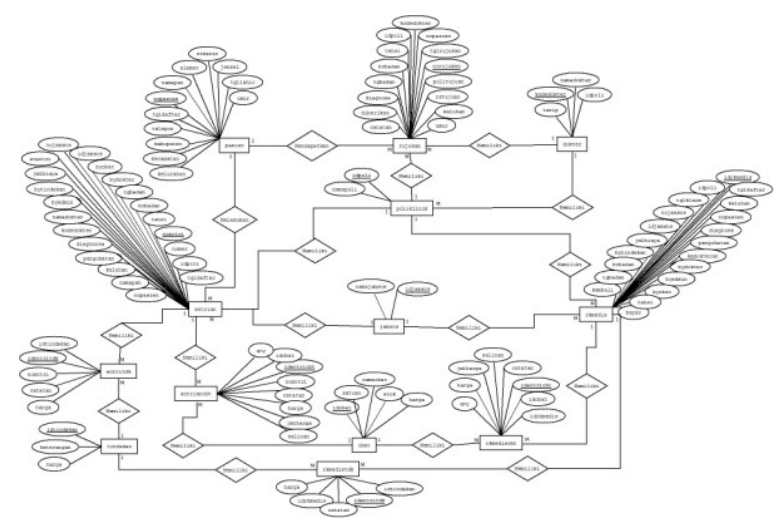

Gambar III.1. Entity Relationship Diagram

(ERD)

b. Logical Relational Structure (LRS)

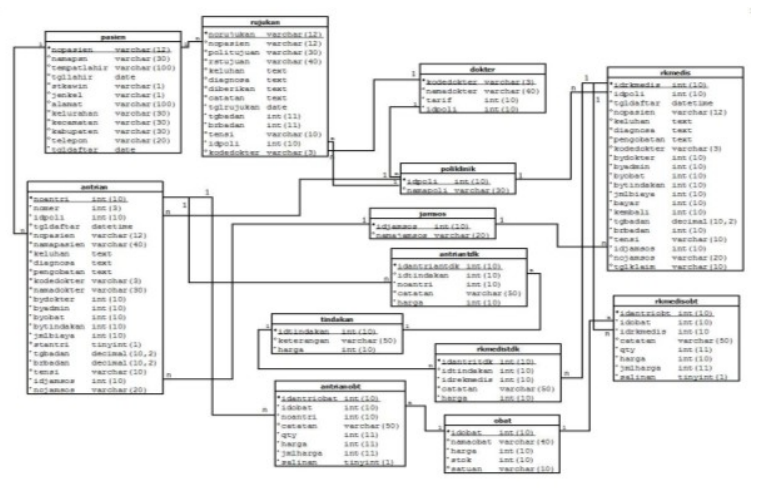

Gambar III.2. Logical Relational Structure

$$
\text { (LRS) }
$$

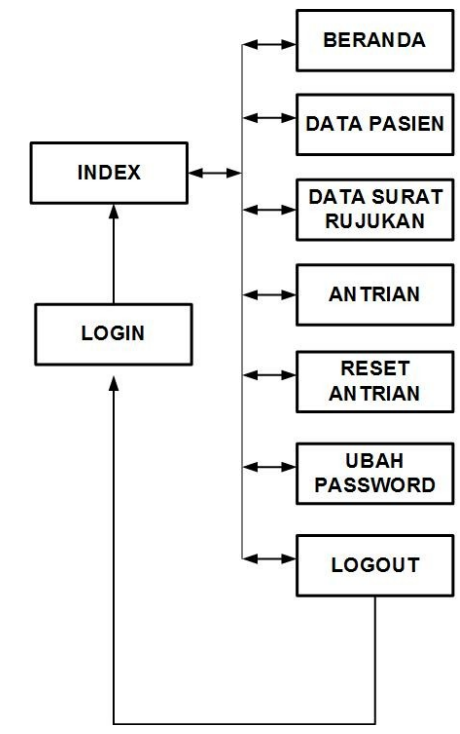

Gambar III.3. Struktur Navigasi Form Pendaftaran

b. Struktur Navigasi Form Dokter

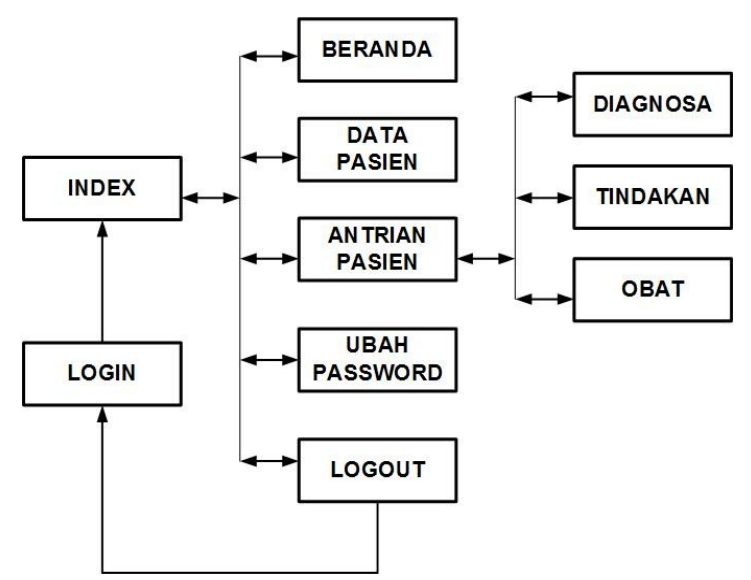

Gambar III.4. Struktur Navigasi Form

Dokter

\subsection{Rancangan Struktur Navigasi}

a. Struktur Navigasi Form Pendaftaran

c. Struktur Navigasi Form Apoteker 


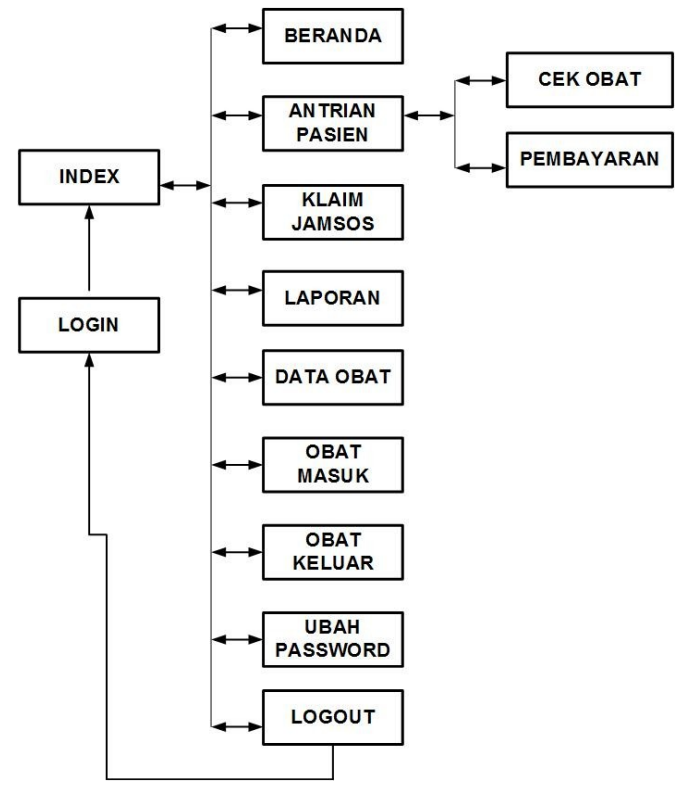

Gambar III.5. Struktur Navigasi Form Apoteker

d. Struktur Navigasi Form Administrator

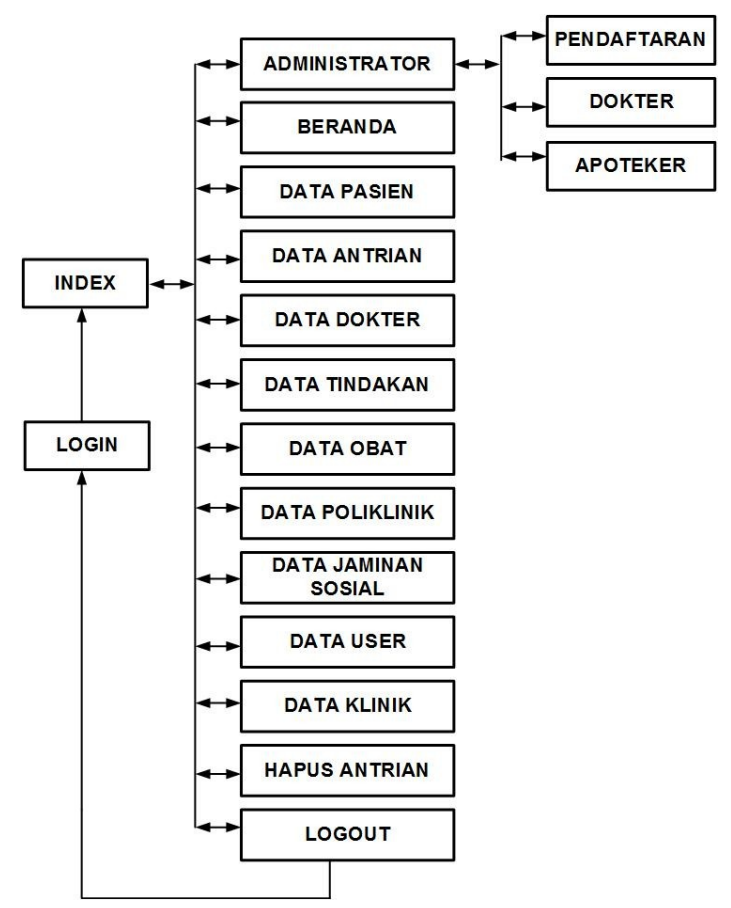

Gambar III.6. Struktur Navigasi Form

Administrator

\subsection{Implementasi dan pengujian Sistem}

a. Implementasi

1) Implementasi Halaman Pendaftaran

a) Login

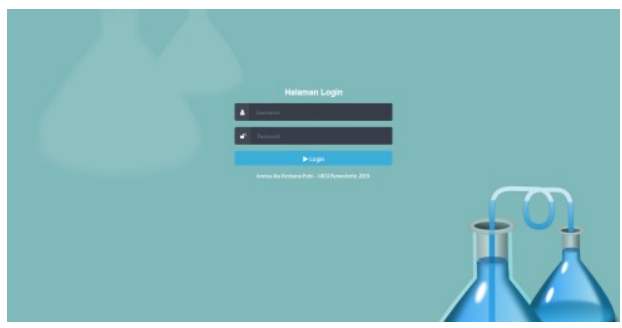

Gambar III.7. Implementasi Halaman Login

b) Beranda

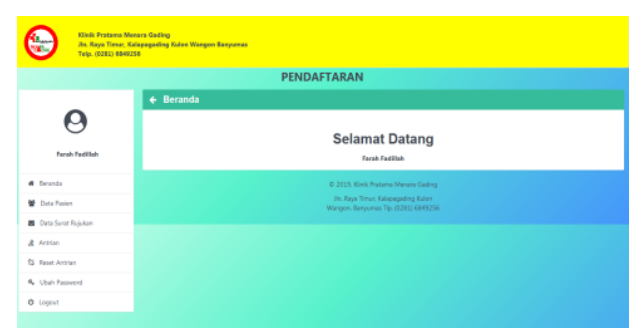

Gambar III.8. Implementasi Halaman Beranda Pendaftaran

2) Implementasi Halaman Dokter 


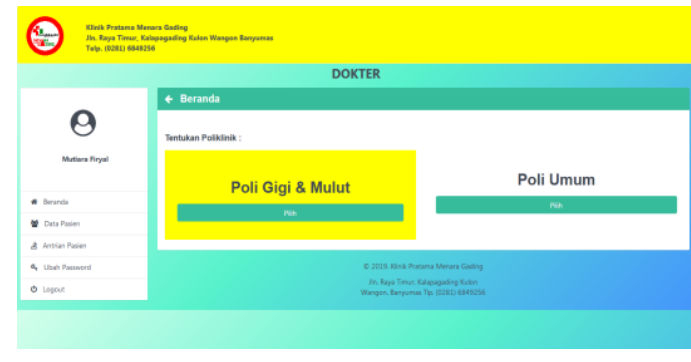

Gambar III.9. Implementasi Halaman Beranda Dokter

3) Implementasi Halaman Apoteker

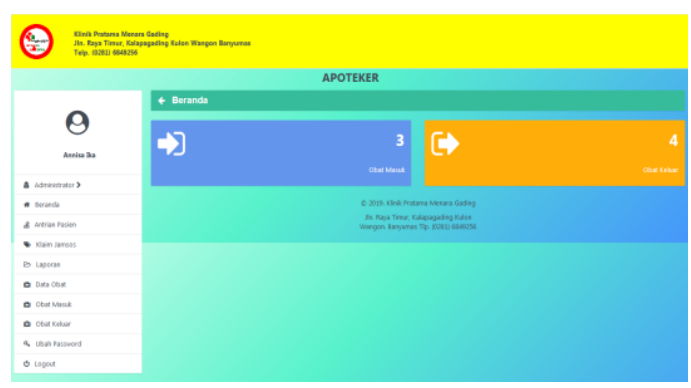

Gambar III.10. Implementasi Halaman

Beranda Apoteker

4) Implementasi

Halaman

Administrator

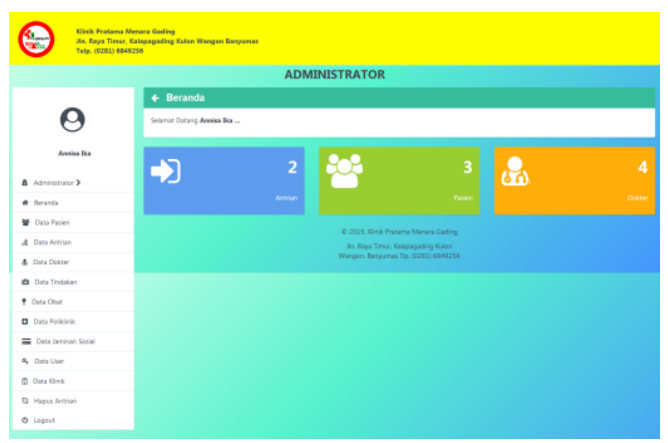

Gambar III.11. Implementasi Halaman Beranda Administrator

\section{b. Pengujian Sistem}

1) Pengujian Black Box Testing Halaman Login Administrator

Tabel III.1. Black Box Testing Halaman Login Administrator

\begin{tabular}{|c|c|c|c|c|c|}
\hline No & $\begin{array}{l}\text { Skenario } \\
\text { Pengujian }\end{array}$ & Test Case & $\begin{array}{l}\text { Hasil Yang } \\
\text { Diharapkan }\end{array}$ & $\begin{array}{c}\text { Hasil } \\
\text { Pengujian }\end{array}$ & Kesimpulan \\
\hline 1 & $\begin{array}{l}\text { Username, } \\
\text { password } \\
\text { tidak di isi } \\
\text { kemudian } \\
\text { klik Login. }\end{array}$ & $\begin{array}{l}\text { Username: } \\
\text { (kosong) } \\
\text { Password. } \\
\text { (kosong) }\end{array}$ & $\begin{array}{l}\text { Sistem akan } \\
\text { menolak akun user } \\
\text { dan menampilkan } \\
\text { pesan"isi isian ini" }\end{array}$ & $\begin{array}{c}\text { Sesuai } \\
\text { harapan }\end{array}$ & Valid \\
\hline 2 & $\begin{array}{l}\text { Username } \\
\text { diisi, } \\
\text { Password } \\
\text { tidak di isi, } \\
\text { kemudian } \\
\text { klik Login }\end{array}$ & $\begin{array}{l}\text { Username: } \\
\text { admin } \\
\text { Password. } \\
\text { (kosong) }\end{array}$ & $\begin{array}{l}\text { Sistem akan } \\
\text { menolak akun user } \\
\text { dan menampilkan } \\
\text { pesan "Isi Isian ini" }\end{array}$ & $\begin{array}{c}\text { Sesuai } \\
\text { harapan }\end{array}$ & Valid \\
\hline 3 & $\begin{array}{l}\text { Username } \\
\text { tidak di isi } \\
\text { dan } \\
\text { Password } \\
\text { di isi. }\end{array}$ & $\begin{array}{l}\text { Username: } \\
\text { (kosong) } \\
\text { Password: } \\
* * * * *\end{array}$ & $\begin{array}{l}\text { Sistem akan } \\
\text { menolak akun user } \\
\text { dan menampilkan } \\
\text { pesan "Isi Isian ini" }\end{array}$ & $\begin{array}{l}\text { Sesuai } \\
\text { harapan }\end{array}$ & Valid \\
\hline
\end{tabular}

2) Pengujian Black Box Testing Halaman Login Pendaftaran

Tabel III.2. Black Box Testing Halaman Login Pendaftaran

\begin{tabular}{|c|c|c|c|c|c|}
\hline No & $\begin{array}{c}\text { Skenario } \\
\text { Pengujian }\end{array}$ & Test Case & $\begin{array}{l}\text { Hasi1 Yang } \\
\text { Diharapkan }\end{array}$ & $\begin{array}{c}\text { Hasil } \\
\text { Pengujian }\end{array}$ & Kesimpulan \\
\hline 1 & $\begin{array}{l}\text { Username, } \\
\text { password } \\
\text { tidak disi } \\
\text { kemudian } \\
\text { klik Login. }\end{array}$ & $\begin{array}{l}\text { Username: } \\
\text { (kosong) } \\
\text { Password: } \\
\text { (kosong) }\end{array}$ & $\begin{array}{l}\text { Sistem akan menolak } \\
\text { akun user dan } \\
\text { menampilkan } \\
\text { pesan"isi isian ini" }\end{array}$ & $\begin{array}{l}\text { Sesuai } \\
\text { harapan }\end{array}$ & Valid \\
\hline 2 & $\begin{array}{l}\text { Username } \\
\text { diisi, } \\
\text { Passord } \\
\text { tidak di isi, } \\
\text { kemudian } \\
\text { klik Login }\end{array}$ & $\begin{array}{l}\text { Username: } \\
\text { daftar } \\
\text { Password: } \\
\text { (kosong) }\end{array}$ & $\begin{array}{l}\text { Sistem akan menolak } \\
\text { akun user dan } \\
\text { menampilkan pesan } \\
\text { "Isi Isian ini" }\end{array}$ & $\begin{array}{l}\text { Sesuai } \\
\text { harapan }\end{array}$ & Valid \\
\hline 3 & $\begin{array}{l}\text { Username } \\
\text { tidak di isi } \\
\text { dan } \\
\text { Password } \\
\text { di isi. }\end{array}$ & $\begin{array}{l}\text { Username: } \\
\text { (kosong) } \\
\text { Password. } \\
\text { *:*:* }\end{array}$ & $\begin{array}{l}\text { Sistem akan menolak } \\
\text { akun user dan } \\
\text { menampilkan pesan } \\
\text { "Isi Isian ini" }\end{array}$ & $\begin{array}{c}\text { Sesuai } \\
\text { harapan }\end{array}$ & Valid \\
\hline
\end{tabular}

3) Pengujian Black Box Testing Halaman Login Dokter 
Tabel III.3. Black Box Testing Halaman Login Dokter

\begin{tabular}{|c|c|c|c|c|c|}
\hline No & $\begin{array}{l}\text { Skenario } \\
\text { Pengujian }\end{array}$ & Test Case & $\begin{array}{l}\text { Hasil Yang } \\
\text { Diharapkan }\end{array}$ & $\begin{array}{c}\text { Hasil } \\
\text { Pengujian }\end{array}$ & Kesimpulan \\
\hline 1 & $\begin{array}{l}\text { Username, } \\
\text { password } \\
\text { tidak di isi } \\
\text { kemudian } \\
\text { klik Login. }\end{array}$ & $\begin{array}{l}\text { Usemame: } \\
\text { (kosong) } \\
\text { Password: } \\
\text { (kosong) }\end{array}$ & $\begin{array}{l}\text { Sistem akan } \\
\text { menolak akun user } \\
\text { dan menampilkan } \\
\text { pesan"isi isian ini" }\end{array}$ & $\begin{array}{c}\text { Sesuai } \\
\text { harapan }\end{array}$ & Valid \\
\hline 2 & $\begin{array}{l}\text { Username } \\
\text { disi, } \\
\text { Password } \\
\text { tidak di isi, } \\
\text { kemudian } \\
\text { klik Login }\end{array}$ & $\begin{array}{l}\text { Usemame: } \\
\text { dokter } \\
\text { Password: } \\
\text { (kosong) }\end{array}$ & $\begin{array}{l}\text { Sistem akan } \\
\text { menolak akun user } \\
\text { dan menampilkan } \\
\text { pesan "Isi Isian ini" }\end{array}$ & $\begin{array}{c}\text { Sesuai } \\
\text { harapan }\end{array}$ & Valid \\
\hline 3 & $\begin{array}{l}\text { Username } \\
\text { tidak di isi } \\
\text { dan } \\
\text { Password di } \\
\text { isi. }\end{array}$ & $\begin{array}{l}\text { Usemame: } \\
\text { (kosong) } \\
\text { Password. } \\
* * * * *\end{array}$ & $\begin{array}{l}\text { Sistem akan } \\
\text { menolak akun user } \\
\text { dan menampilkan } \\
\text { pesan "Isi Isian ini" }\end{array}$ & $\begin{array}{l}\text { Sesuai } \\
\text { harapan }\end{array}$ & Valid \\
\hline
\end{tabular}

4) Pengujian Black Box Testing Halaman Login Apoteker

Tabel III.4. Black Box Testing Halaman Login Apoteker

\begin{tabular}{|c|c|c|c|c|c|}
\hline No & $\begin{array}{c}\text { Skenario } \\
\text { Pengujian }\end{array}$ & Test Case & $\begin{array}{l}\text { Hasil Yang } \\
\text { Diharapkan }\end{array}$ & $\begin{array}{c}\text { Hasil } \\
\text { Pengujian }\end{array}$ & Kesimpulan \\
\hline 1 & $\begin{array}{l}\text { Username, } \\
\text { password } \\
\text { tidak di isi } \\
\text { kemudian } \\
\text { klik Login. }\end{array}$ & $\begin{array}{l}\text { Username: } \\
\text { (kosong) } \\
\text { Password: } \\
\text { (kosong) }\end{array}$ & $\begin{array}{l}\text { Sistem akan } \\
\text { menolak akun user } \\
\text { dan menampilkan } \\
\text { pesan"isi isian ini" }\end{array}$ & $\begin{array}{l}\text { Sesuai } \\
\text { harapan }\end{array}$ & Valid \\
\hline 2 & $\begin{array}{l}\text { Username } \\
\text { diisi, } \\
\text { Password } \\
\text { tidak di isi, } \\
\text { kemudian } \\
\text { klik Login }\end{array}$ & $\begin{array}{l}\text { Username: } \\
\text { obat } \\
\text { Password: } \\
\text { (kosong) }\end{array}$ & $\begin{array}{l}\text { Sistem akan } \\
\text { menolak akun user } \\
\text { dan menampilkan } \\
\text { pesan "Isi Isian ini" }\end{array}$ & $\begin{array}{c}\text { Sesuai } \\
\text { harapan }\end{array}$ & Valid \\
\hline 3 & $\begin{array}{l}\text { Username } \\
\text { tidak di isi } \\
\text { dan } \\
\text { Password } \\
\text { di isi. }\end{array}$ & $\begin{array}{l}\text { Username: } \\
\text { (kosong) } \\
\text { Password. } \\
*: * * *\end{array}$ & $\begin{array}{l}\text { Sistem akan } \\
\text { menolak akun user } \\
\text { dan menampilkan } \\
\text { pesan "Isi Isian ini" }\end{array}$ & $\begin{array}{l}\text { Sesuai } \\
\text { harapan }\end{array}$ & Valid \\
\hline
\end{tabular}

\section{KESIMPULAN}

Berdasarkan hasil penelitian dan pembahasan dapat disimpulkan sebagai berikut:

a. Pelayanan kesehatan khususnya untuk proses administrasi pasien di Klinik Pratama Menara Gading belum optimal sepenuhnya.

b. Dengan adanya sistem informasi administrasi klinik rawat jalan dari segi pelayanan dapat membantu meningkatkan kualitas pelayanan kesehatan pada klinik tersebut.

c. Dengan adanya sistem informasi administrasi dapat mengurangi terjadinya kesalahan dan duplikasi data dalam mengelola data.

d. Dengan adanya sistem yang terkomputerisasi dapat memudahkan dan mempercepat proses pembuatan laporan yang lebih akurat dan tingkat resiko kesalahannya yang kecil.

\section{DAFTAR PUSTAKA}

[1] Hadiyati, I., Sekarwana, N., Sunjaya, D. K., \& Setiawati, E. P. (2017). Konsep Kualitas Pelayanan Kesehatan berdasar atas Ekspektasi Peserta Jaminan Kesehatan Nasional. Majalah Kedokteran Bandung, 49(2), 102-109.

[2] Handayani, T., \& Feoh, G. (2016). Perancangan Sistem Informasi Rekam Medis Berbasis Web (Studi Kasus Di Klinik Bersalin Sriati Kota Sungai Penuh - Jambi). Jurnal Teknologi Informasi Dan Komputer, 2(2), 226236.

[3] Magdalena, H., \& Ramadhan, F. C. (2018). Aplikasi Registrasi Pasien Berbasis Web di Unit Gawat Darurat ( Studi Kasus : Rumah Sakit Bakti Timah Pangkalpinang ). Fountain of Informatics Journal, 3(2), 54-63.

[4] Rahmayu, M. (2016). Rancang Bangun Sistem Informasi Pada Rumah Sakit Dengan Layanan Intranet Menggunakan Metode Waterfall. Jurnal Evolusi, 4(2), 33-40.

[5] Sundari, J. (2016). Sistem Informasi Pelayanan Puskesmas Berbasis Web. IJSE - Indonesian Journal on Software Engineering, 2(1), 44-49.

[6] Supriyanta, \& Nussy, E. N. D. F. R. (2016). Perancangan Website Sebagai 
Media Informasi Panti Asuhan Batu Penjuru Kulon Progo. Journal Speed, 8(2), 17-22.

[7] Syahabiah, Gusmelia Testiana, R. M. F. (2016). Sistem Informasi Administrasi Pasien Pada Klinik Su'adah Palembang Berbasis Web (Studi Kasus: BPS Provinsi Sumsel). Jurnal Sistem Informasi, 2(1), 1-10.

[8] Syahriani. (2018). Sistem Informasi Pelayanan Kesehatan Berbasis Web pada Puskesmas Pluit Jakarta. Jurnal Teknik Komputer, IV(2), 105-111. 